\title{
Adenosine 5'-triphosphate stimulates the increase of TGF- $\beta 1$ in rat mesangial cells under high-glucose conditions via reactive oxygen species and ERK1/2
}

\author{
Lin-ping $\mathrm{QU}^{1}$, Hong XUE ${ }^{1}$, Ping YUAN${ }^{1}$, Li ZHOU ${ }^{1}$, Tai YAO ${ }^{1}$, Yu HUANG ${ }^{2}$, Li-min LU ${ }^{1, *}$ \\ ${ }^{1}$ Department of Physiology and Pathophysiology, Shanghai Medical College, Fudan University, Shanghai 200032, China; ${ }^{2}$ Department \\ of Physiology and Institute of Vascular Medicine, The Chinese University of Hong Kong, Hong Kong, China
}

\begin{abstract}
Aim: To investigate the role of adenosine 5'-triphosphate (ATP)-induced generation of reactive oxygen species (ROS) and phosphorylation of extracellular signal-regulated kinase $1 / 2$ (ERK1/2) in the production of transforming growth factor- $\beta 1$ (TGF- $\beta 1$ ) in cultured rat glomerular mesangial cells under high-glucose conditions.

Methods: Subconfluent glomerular mesangial cells were serum-starved for $24 \mathrm{~h}$ and pretreated with suramin, diphenylenechloride iodonium (DPI) or PD98059 followed by stimulation with a high concentration of glucose (30 mmol/L D-glucose) or ATP (300 $\mu$ mol/L). Extracellular and total ATP and ROS production were detected using commercially available kits. Phosphorylation of ERK1/2 was evaluated by Western blot. TGF- $\beta 1$ mRNA expression was examined by real-time PCR.

Results: Suramin had a dose-dependent inhibitory effect on the generation of ROS induced by high glucose. Extracellular ATP production by mesangial cells increased markedly after a 2-h incubation with high glucose. ROS production was upregulated in mesangial cells after $5 \mathrm{~min}$ incubation with $300 \mu \mathrm{mol} / \mathrm{L}$ ATP and was sustained for $120 \mathrm{~min}$. ERK1/2 was significantly activated after 5 min incubation of mesangial cells with ATP, this activation was partially inhibited by DPI. The effects of high glucose on TGF- $\beta 1$ mRNA were markedly inhibited by suramin, DPI or PD98059.

Conclusion: Our results suggest that a high concentration of glucose increases the extracellular levels of ATP in mesangial cells within a short time-frame. ATP, in turn, activates ERK1/2, an effect which is at least partially dependent on ROS, which results in the upregulation of TGF- $\beta 1$.
\end{abstract}

Keywords: diabetic nephropathy; reactive oxygen species; adenosine 5'-triphosphate; extracellular signal-regulated kinase 1/2; transforming growth factor- $\beta 1$; mesangial cells

Acta Pharmacologica Sinica (2009) 30: 1601-1606; doi: 10.1038/aps.2009.155

\section{Introduction}

Adenosine 5'-triphosphate (ATP) is not only an important source of energy for cells, but also an important extracellular signaling molecule that modulates various cell functions. The release of ATP from the cell occurs by conductive transportation, facilitated transport and exocytosis ${ }^{[1]}$. After leaving the cell, ATP can bind to two subclasses of purinergic P2 receptors on the cell membrane. P2X receptors are non-selective cation channels while P2Y are G-protein-coupled receptors ${ }^{[2]}$. Both these receptors are composed of several subtypes ${ }^{[3,4]}$. In the extracellular space, ATP is rapidly degraded into adenosine diphosphate (ADP), adenosine monophosphate (AMP) and adenosine by multiple ecto-enzymes, including ectonucleotide

* To whom correspondence should be addressed.

E-mail lulimin@shmu.edu.cn

Received 2009-07-15 Accepted 2009-09-16 triphosphate diphosphohydrolases, ectonucleotide pyrophosphatases/phosphodiesterases and alkaline phosphatases ${ }^{[1]}$. Therefore, ATP is thought of as a local mediator that acts in an autocrine or paracrine manner within tissues and tissue microenvironments ${ }^{[5]}$.

Extracellular ATP in the kidney, which is produced by tubular epithelial cells, endothelial cells, smooth muscle cells, platelets and perivascular nerves, can act on glomeruli, renal tubules, collecting ducts and renal blood vessels by binding to either P2X or P2Y receptors ${ }^{[1,6-9]}$. ATP has been shown to regulate renal blood flow, glomerular filtration rate, water and salt reabsorption and tubuloglomerular feedback ${ }^{[1,7,10,11]}$.

Mesangial cells play a critical role in the initiation and progression of diabetic nephropathy and their abnormal proliferation and secretion of extracellular matrix (ECM) promotes glomerular sclerosis ${ }^{[12]}$. High glucose levels induce the generation of reactive oxygen species (ROS) by mesangial cells; ROS, 
in turn, activate mitogen-activated protein kinase (MAPK) in mesangial cells, leading to their secretion of transforming growth factor- $\beta 1$ (TGF- $\beta 1$ ) and fibronectin ${ }^{[13]}$. In addition, extracellular ATP has been shown to stimulate ROS generation in macrophages and microglia ${ }^{[14,15]}$. As there is evidence showing that mesangial cells express almost all P2 receptor subtypes, it became interesting to us to determine whether, under high-glucose conditions, ATP and $\mathrm{P} 2$ receptors mediate the production of ROS by mesangial cells.

This study was aimed at evaluating the role of extracellular ATP-induced generation of ROS and phosphorylation of extracellular signal-regulated kinase $1 / 2$ (ERK1/2) in TGF- $\beta 1$ synthesis under high-glucose conditions in cultured rat renal mesangial cells.

\section{Materials and methods Drugs and chemicals}

Low-glucose Dulbecco's Modified Eagle's Medium (DMEM), D-glucose, mannitol, adenosine $5^{\prime}$-triphosphate (ATP), suramin, diphenylenechloride iodonium (DPI) and PD98059 were purchased from Sigma (St Louis, MO, USA). Rabbit anti-rat p44/42 MAP Kinase (ERK1/2) and phospho-p44/42 MAP Kinase (p-ERK1/2) antibodies were purchased from Cell Signaling Technology (Danvers, MA, USA). Horseradish peroxidase-conjugated goat anti-rabbit IgG antibody was purchased from Zhongshan Golden Bridge Biotechnology (Beijing, China). Proteinase inhibitor was purchased from Upstate (Waltham, MA, USA). Oligo dT, dNTP and Rnasin were purchased from Shenergy Biocolor BioScience and Technology (Shanghai, China), M-MLV reverse transcriptase was purchased from Promega (WI, USA), SYBR Green quantitative real-time (qRT)-PCR Master Mix was purchased from Toyobo (Osaka, Japan). Primers for RT-PCR were synthesized by Sangon Biological Engineering Technology and Services (Shanghai, China). All other chemicals and reagents were of analytical grade.

\section{Cell culture}

The rat glomerular mesangial cell line (HBZY-1) purchased from China Center for Type Culture Collection (Wuhan, China) was cultured in low-glucose DMEM $(5.5 \mathrm{mmol} / \mathrm{L}$ D-glucose) supplemented with $10 \%$ neonatal bovine serum in an atmosphere of $95 \% \mathrm{O}_{2}$ and $5 \% \mathrm{CO}_{2}$ at $37^{\circ} \mathrm{C}$. Before each experiment, cells were pre-incubated with DMEM supplemented with $1 \%$ neonatal bovine serum for $24 \mathrm{~h}$. All antagonists were added $30 \mathrm{~min}$ in advance of changing to highglucose culture media or ATP addition. High-glucose culture media was made by supplementing low-glucose DMEM (5.5 $\mathrm{mmol} / \mathrm{L} \mathrm{D}$-glucose) with additional D-glucose for a final D-glucose concentration of $30 \mathrm{mmol} / \mathrm{L}$.

\section{Reactive oxygen species assay}

Experiments were performed using the reactive oxygen species assay kit (Beyotime, Haimen, China) according to the manufacturer's instructions. Briefly, cells seeded in 96-well plates were incubated with $10 \mu \mathrm{mol} / \mathrm{L}$ DCFH-DA probes
(100 $\mu \mathrm{L} /$ well) at $37^{\circ} \mathrm{C}$ for $30 \mathrm{~min}$ and then washed with PBS 3 times in order to remove residual probes. The fluorescence intensity at $488 \mathrm{~nm}$ excitation wavelength and $525 \mathrm{~nm}$ emission wavelength was measured using a luminometer (Tecan, Switzerland).

\section{ATP detection assay}

ATP production was analyzed using the luminescence ATP detection assay kit (Perkin Elmer, Boston, MA, USA) according to the manufacturer's instructions. The principle of this assay is based on the production of light caused by the reaction of ATP with added luciferase and D-luciferin. Rat mesangial cells seeded in 96-well plates were incubated with the substrate solution (luciferase and D-luciferin, $50 \mu \mathrm{L} /$ well), shaken for $5 \mathrm{~min}$ and placed in the dark for $10 \mathrm{~min}$. The cells were then placed into the test chamber of a luminometer and the emission of light was recorded and used to estimate the relative levels of extracellular ATP. In order to determine the relative levels of total ATP, the cells were further treated with lysis solution ( $50 \mu \mathrm{L} /$ well), shaken for $5 \mathrm{~min}$ and placed in dark for $10 \mathrm{~min}$, then measured in the luminometer.

\section{Western blot}

Rat mesangial cells were lysed in $1 \times$ sodium dodecyl sulfate (SDS) supplemented with proteinase inhibitor at a dilution of 1:25. Protein concentrations were measured using the BCA protein assay kit (Shenergy Biocolor BioScience and Technology, Shanghai, China). Thirty micrograms of protein lysate was electrophoresed on a $12 \%$ polyacrylamide SDS gel and transblotted onto a PVDF membrane at $270 \mathrm{~mA}$ for $90 \mathrm{~min}$. After transfer, the membranes were blocked with 5\% skim milk in Tris-buffered saline (TBS) and 0.1\% Tween (TBS/ Tween) for $1 \mathrm{~h}$ at room temperature with gentle rocking. The membranes were then incubated with rabbit anti-rat phosphop44/42 MAPK antibodies (1:1000 in 5\% skim milk in TBS/ Tween) and incubated overnight at $4{ }^{\circ} \mathrm{C}$. The following day, the membranes were washed 3 times ( 15 min per wash) with TBS/Tween and incubated with secondary anti-rabbit antibody (1:2000) for $1 \mathrm{~h}$ at room temperature. The membranes were then washed again 3 times, developed using the enhanced chemiluminescent (ECL) detection kit (Pierce Biotechnology, IL, USA) according to the manufacturer's instructions and exposed to X-ray film (Kodak, Rochester, NY, USA) for $0.5-5 \mathrm{~min}$ as necessary to visualize signals. Additionally, the membranes were treated with stripping buffer $(0.5 \mathrm{~mol} / \mathrm{L}$ $\mathrm{NaCl}, 0.5 \mathrm{~mol} / \mathrm{L}$ acetic acid) for $1 \mathrm{~h}$ at room temperature. After three 15-min washes, the membranes were re-blocked with $5 \%$ skim milk in TBS/Tween for $1 \mathrm{~h}$ at room temperature. Afterwards, the membranes were incubated with rabbit anti-rat p44/42 MAPK antibodies (1:1000), washed, incubated with secondary antibody and developed as described above. The relative intensity of the bands exposed on the films was quantified using Smart viewer software (Furi Technology Co, Shanghai, China). The results are expressed as a ratio of phosphorylated to total ERK1/2. 


\section{Isolation of total RNA and synthesis of cDNA}

Rat mesangial cells were lysed in TRIZOL and total RNA was isolated. The amount of RNA isolated was determined by measuring the specific absorbance at $260 \mathrm{~nm}$. One microgram of total RNA was used for cDNA synthesis in a $20 \mu \mathrm{L}$ reaction mixture that contained $1 \mu \mathrm{g}$ Oligo dT, $10 \mathrm{mmol} / \mathrm{L} \mathrm{dNTP}, 20 \mathrm{U}$ RNase inhibitor and $200 \mathrm{U}$ M-MLV reverse transcriptase. A $1-\mu \mathrm{L}$ aliquot of the resulting single-strand cDNA was used for qRT-PCR.

\section{Quantitative Real-time PCR}

TGF- $\beta 1$ and glyceraldehyde 3-phosphate dehydrogenase (GAPDH) primer sequences are listed in Table 1. SYBR Green qRT-PCR was used to quantify the relative abundance of target mRNA in the samples. qRT-PCR procedures were performed according to the manufacturer's instructions. The accumulated fluorescence was detected using the iCycler iQ RT-PCR detection system (Bio-Rad, Hercules, CA, USA). The PCR amplification conditions were: $95^{\circ} \mathrm{C}$ for $10 \mathrm{~min}$ and 40 cycles of $95{ }^{\circ} \mathrm{C}$ for $30 \mathrm{~s}, 62{ }^{\circ} \mathrm{C}$ for $45 \mathrm{~s}$ and $72{ }^{\circ} \mathrm{C}$ for $1 \mathrm{~min}$. In addition, the amplified products were subjected to a stepwise increase in temperature from $55^{\circ} \mathrm{C}$ to $95^{\circ} \mathrm{C}$ and dissociation curves were constructed. Target mRNA levels were quantified by measuring the threshold cycle (when fluorescence is statistically significant above the background) and comparing it against a calibration curve. The relative amount of each mRNA was normalized to the housekeeping gene, GAPDH. Each sample was run and analyzed in triplicate.

Table 1. PCR primer pairs used to amplify TGF- $\beta 1$ and GAPDH cDNA fragments.

\begin{tabular}{llccc}
\hline Target & \multicolumn{2}{l}{ Oligonucleotide sequence } & $\mathrm{Tm}^{\circ} \mathrm{C}$ & bp \\
\hline TGF-B1 & F & 5'-TGG CGT TAC CTT GGT AAC C-3' & 61 & 277 \\
& R & 5'-GGT GTT GAG CCC TTT CCA G-3' & 62 & \\
GAPDH & F & 5'-CCC TTC ATT GAC CTC AAC TAC ATG-3' & 60 & 216 \\
& R & 5'-CTT CTC CAT GGT GGT GAA GAC-3' & 60 & \\
\hline
\end{tabular}

F, forward primer; R, reverse primer; Tm, melting temperature.

\section{Statistical analysis}

The results are expressed as the mean \pm SEM. Data were analyzed using the one-way ANOVA with the Bonferroni correction for all pairwise comparisons. A $P$-value of $<0.05$ was considered statistically significant.

\section{Results}

Effect of suramin, a nonspecific P2 receptor antagonist, on ROS generation induced by high glucose

Suramin exhibited a dose-dependent inhibitory effect on the increased generation of ROS induced by high glucose for $2 \mathrm{~h}$ in rat mesangial cells; suramin at $100 \mu \mathrm{mol} / \mathrm{L}$ had an obvious effect on the diminishment of ROS generation $(P<0.05$ vs HG, high glucose; Figure 1).

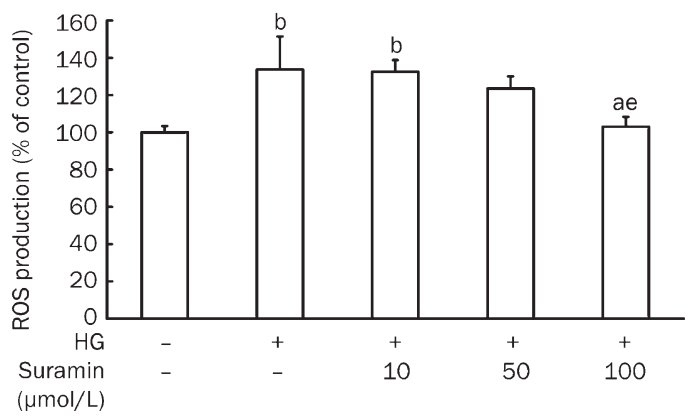

Figure 1. Effect of suramin on the generation of ROS induced by high glucose in mesangial cells. Rat mesangial cells were cultured under high glucose (30 mmol/L D-glucose) conditions for $2 \mathrm{~h}$. In order to explore the involvement of extracellular ATP in the generation of ROS, the cells were pretreated with suramin, a nonspecific $\mathrm{P} 2$ receptor antagonist, at the indicated concentrations for $30 \mathrm{~min}$. $n=4-6$. Mean \pm SEM. ${ }^{a} P>0.05$ vs control; ${ }^{\mathrm{b}} \mathrm{P}<0.05$ vs control; ${ }^{\mathrm{e}} \mathrm{P}<0.05$ vs $\mathrm{HG}$ (high glucose).

\section{Effect of high glucose on extracellular ATP levels}

Extracellular ATP levels increased markedly after incubation of rat mesangial cells in high-glucose media for $2 \mathrm{~h}(P<0.05$ vs low-glucose control), but ATP levels did not change in cells cultured in media supplemented with $24.5 \mathrm{mmol} / \mathrm{L}$ mannitol for the same time period as the iso-osmolar (Figure 2A). Total ATP levels were measured after lysing rat mesangial cells.
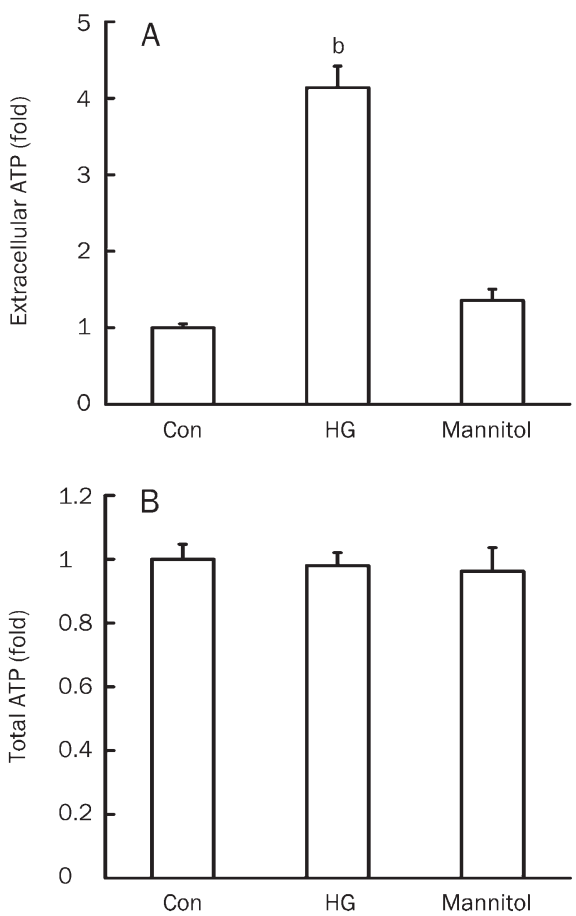

Figure 2. Effect of high glucose on extracellular and total ATP levels in mesangial cells. Rat mesangial cells were cultured under low-glucose (5.5 mmol/L D-glucose), high-glucose (HG, $30 \mathrm{mmol} / \mathrm{L} \mathrm{D-glucose),} \mathrm{or}$ iso-osmolar ( $5.5 \mathrm{mmol} / \mathrm{L} \mathrm{D-glucose}+24.5 \mathrm{mmol} / \mathrm{L}$ mannitol) conditions for $2 \mathrm{~h}$, extracellular (A) and total (B) ATP levels were measured. $n=6$. Mean \pm SEM. ${ }^{\mathrm{b}} \mathrm{P}<0.05$ vs control. 
There were no obvious differences in total ATP levels between low-glucose and high-glucose groups. As the intracellular ATP levels showed at least 10 000-fold higher than extracelluar levels ${ }^{[1,5]}$, the possiblity of the difference in cell numbers could be excluded (Figure 2B).

\section{Effect of extracellular ATP on ROS generation}

ATP at $300 \mu \mathrm{mol} / \mathrm{L}$ induced an obvious increase in the generation of ROS ( $P<0.05$ vs control), while ATP at $100 \mu \mathrm{mol} / \mathrm{L}$ only slightly enhanced ROS generation ( $P>0.05$ vs control). Lower concentration of ATP $(10 \mu \mathrm{mol} / \mathrm{L})$ had almost no effect on the generation of ROS (Figure 3A). In order to determine whether the effect of ATP was long-lasting, cells were exposed to 300 $\mu \mathrm{mol} / \mathrm{L}$ ATP for 5, 15, 30, 60, or $120 \mathrm{~min}$. We observed that ROS generation was upregulated after exposure of the cells to ATP for $5 \mathrm{~min}$ and was followed by a sustained increase in ROS generation at $120 \mathrm{~min}(P<0.05$ vs control); the largest amount of ROS was observed after 15 min exposure to ATP (Figure 3B).

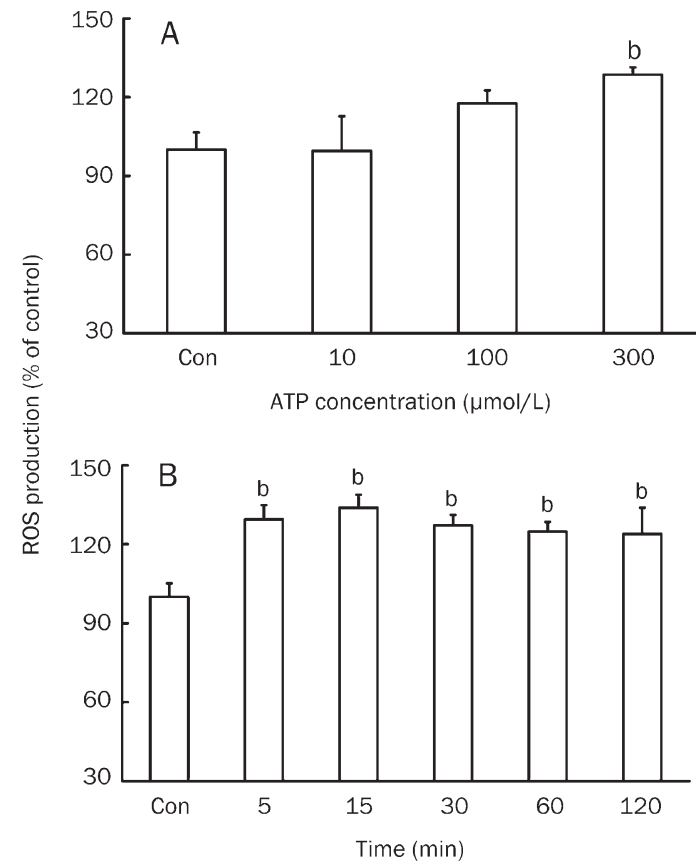

Figure 3. Effect of extracellular ATP on ROS production in mesangial cells cultured under low-glucose conditions. (A) ROS levels were measured in rat mesangial cells treated with ATP for $5 \mathrm{~min}$ at 10,100 , or $300 \mu \mathrm{mol} / \mathrm{L}$. $n=5-6$. (B) The effective concentration of $300 \mu \mathrm{mol} / \mathrm{L}$ ATP was selected to treat mesangial cells for 5-120 min in order to observe the continuous effect of ATP on ROS production. $n=6$. Mean \pm SEM. ${ }^{b} P<0.05$ vs control.

\section{Effect of extracellular ATP on ERK1/2 phosphorylation}

Phosphorylation of ERK1/2, one of the downstream targets of ROS, was assessed by measuring the level of $\mathrm{p}$-ERK $1 / 2$ protein and comparing it to total level of ERK1/2 in rat mesangial cells. ERK1/2 was largely activated by exposure to 300 $\mu \mathrm{mol} / \mathrm{L} \mathrm{ATP}$ for $5 \mathrm{~min}(P<0.05$ vs control). Longer exposure to ATP led to a gradual decrease in ERK1/2 phosphorylation. After a 60 min exposure time, the levels of p-ERK1/2 were much less than those in the control $(P<0.05$ vs control; Figure $4 \mathrm{~A})$. In mesangial cells, ROS are mostly generated by NADPH oxidase $^{[16]}$. Therefore, we used the NADPH oxidase inhibitor DPI to assess the effect of ROS inhibition on ATP-induced ERK1/2 phosphorylation. We found that $1 \mu \mathrm{mol} / \mathrm{L}$ DPI partially inhibited ATP-induced phosphorylation of ERK1/2 $(P<0.05$ vs control, $P<0.05$ vs ATP; Figure $4 \mathrm{~B})$.

A
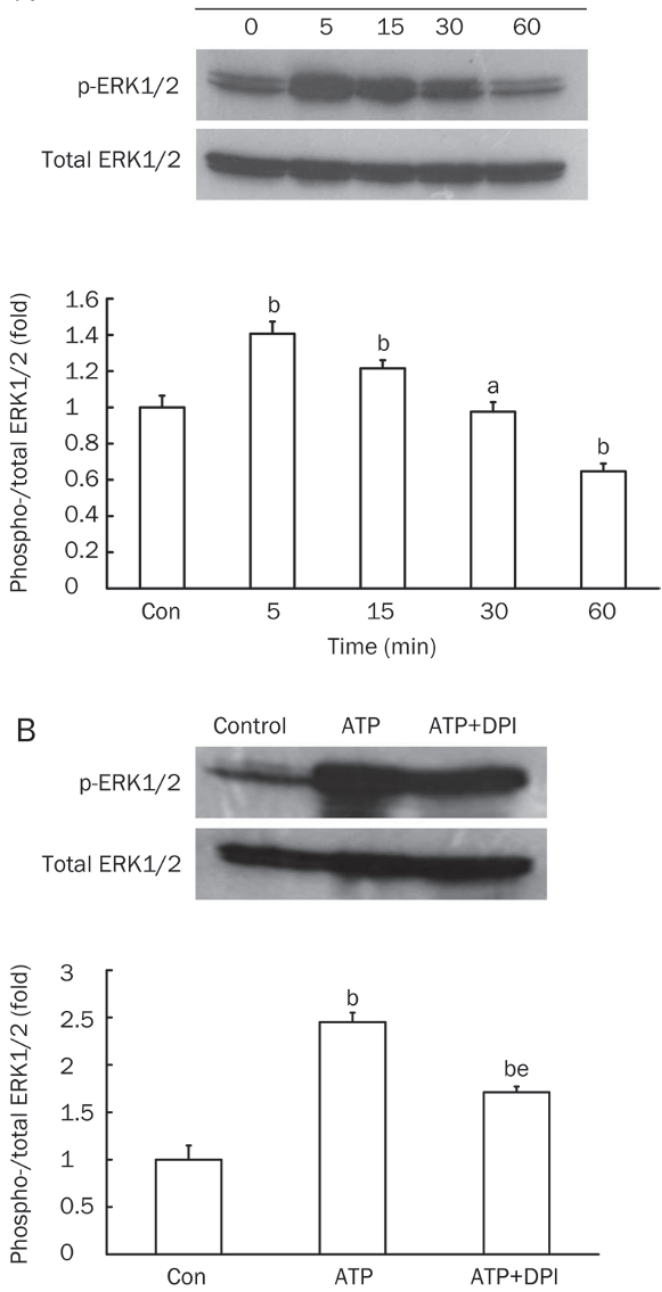

Figure 4. Effect of extracellular ATP on ERK1/2 phosphorylation in mesangial cells cultured under low-glucose conditions. Western blot analysis of p-ERK1/2 in rat mesangial cells (normalized to total ERK1/2). (A) Cells were treated with $300 \mu \mathrm{mol} / \mathrm{L}$ ATP for 5 to $60 \mathrm{~min}$. (B) Cells were pretreated with the NADPH oxidase inhibitor DPI ( $1 \mu \mathrm{mol} / \mathrm{L})$ for $30 \mathrm{~min}$ in order to explore whether ROS were involved in ATP-induced ERK1/2 phosphorylation. $n=4$. Mean \pm SEM. ${ }^{\mathrm{a}} P>0.05$ vs control; ${ }^{\mathrm{b}} P<0.05$ vs control; ${ }^{\mathrm{e}} \mathrm{P}<0.05$ vs ATP.

\section{TGF- $\beta 1$ mRNA levels under high-glucose conditions}

Increased renal TGF- $\beta 1$ bioactivity during high-glucose conditions is an important factor in the pathogenesis of diabetic 
nephropathy. TGF- $\beta 1$ mRNA levels were much higher when rat mesangial cells were cultured in high-glucose media than when cultured in low-glucose media $(P<0.05$ vs control). However, this increase was attenuated by suramin (100 $\mu \mathrm{mol} / \mathrm{L})$, DPI ( $1 \mu \mathrm{mol} / \mathrm{L})$ and the ERK kinase (MEK)-specific inhibitor PD98059 (50 $\mathrm{mol} / \mathrm{L})$ (Figure 5).

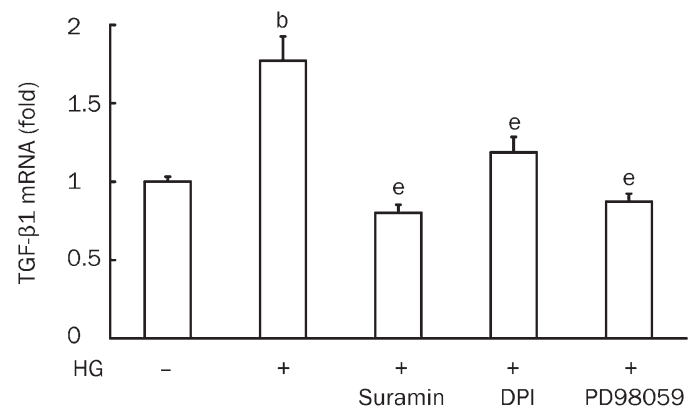

Figure 5. qRT-PCR analysis of TGF- $\beta 1 \mathrm{mRNA}$ levels. Cells were pretreated with suramin $(100 \mu \mathrm{mol} / \mathrm{L})$, DPI $(1 \mu \mathrm{mol} / \mathrm{L})$ or PD98059 $(50 \mu \mathrm{mol} / \mathrm{L})$ for $30 \mathrm{~min}$ before being cultured in high glucose (30 mmol/L D-glucose) media for 2 h. $n=4$. Mean \pm SEM. ${ }^{b} P<0.05$ vs control; ${ }^{e} P<0.05$ vs HG (high glucose).

\section{Discussion}

Diabetic nephropathy is one of the most common complications associated with diabetes and is a major cause of pathology in chronic renal dysfunction. In diabetic nephropathy, mesangial cells make a major contribution to glomerular sclerosis by producing increased amounts of ECM in response to hyperglycemia; TGF- $\beta 1$ is considered to be a major cytokine that modulates the increased production of ECM since it promotes matrix synthesis and reduces its degradation. In addition, ROS and ERK1/2, both of which signal upstream of TGF- $\beta 1$, play a significant part in the kidney damage that results from hyperglycemia.

Previously, it was reported that mesangial cells produce increased levels of ATP when exposed to high-glucose conditions leading to the stimulation of TGF- $\beta 1$ production and ECM secretion $^{[17]}$. However, the role of ROS and ERK1/2 in this process is not known.

Our studies suggest that high-glucose levels promote the production of extracellular ATP level in rat mesangial cells. In contrast to previous studies, we cultured rat mesangial cells in high-glucose media for $2 \mathrm{~h}$ rather than 10-15 d. We found that extracellular ATP levels were increased within $2 \mathrm{~h}$ in response to high glucose, suggesting that high glucose can increase extracellular ATP levels in a relatively short period of time. This effect may depend on the increased release of ATP, decreased ecto-enzyme activity or both. It has been largely shown that the release of ATP into the extracellular milieu is mediated by ATP-permeable release channels, which are similar to voltage-dependent anion channels of the outer mitochondrial membrane, adenine nucleotide transporters or adenine nucleotide/nucleoside exchangers and ATP-filled vesicles $^{[5]}$. In addition, several secondary messengers have been shown to modulate ATP release by elevating intracellular $\mathrm{Ca}^{2+}$ levels and activating the phosphatidylinositol-3- (PI-3K) and Rho kinases. These three signaling pathways have also been shown to be activated under high-glucose conditions in renal mesangial cells, which may result in the stimulation of ATP release ${ }^{[17]}$. We were not able to determine ecto-enzyme activity in response to high glucose levels after $2 \mathrm{~h}$; therefore, these studies will be further assessed in future studies. Incubation of rat mesangial cells with iso-osmolar mannitol did not lead to an increase in extracellular ATP, indicating that the effect induced by high glucose is not dependent on increased osmolality.

In human eosinophils, production of reactive oxygen metabolites increases in response to ATP in a dose-dependent manner, with the maximum concentration of metabolites being reached after $5 \mathrm{~min}$ of exposure to $\mathrm{ATP}^{[18]}$. Primary rat microglial cells stimulated with ATP rapidly generate hydrogen peroxide $\left(\mathrm{H}_{2} \mathrm{O}_{2}\right)$ through the activation of NADPH oxidase. $\mathrm{H}_{2} \mathrm{O}_{2}$ production was sustained for at least $90 \mathrm{~min}$ after stimulation $^{[15]}$. Additionally, ATP-induced apoptosis in murine macrophages is mediated in part by ROS produced by NADPH oxidase $\mathrm{e}^{[14]}$. Our results show that exposure of rat mesangial cells to $300 \mu \mathrm{mol} / \mathrm{L}$ ATP results in rapid and continuous generation of ROS; non-specific antagonist to P2 receptor suramin inhibits high glucose-induced ROS production. These results suggested a role for ATP in high glucose-induced ROS generation in rat mesangial cell. The concentration of ATP used here is similar to that previously reported ${ }^{[14,15,18]}$ and similar to that which has been previously shown to induce proliferation and abnormal secretion of TGF- $\beta 1$ and ECM in mesangial cells ${ }^{[17,19,20]}$. Studies have shown that the generation of ROS induced by ATP is associated with an increase in intracellular $\mathrm{Ca}^{2+}$ levels ${ }^{[14,15,18]}$. The ATP receptors P2X and P2Y can mediate $\mathrm{Ca}^{2+}$ upregulation; however, while $\mathrm{P} 2 \mathrm{X}$ is dependent on $\mathrm{Ca}^{2+}$ influx, P2Y is dependent on mobilization from intracellular $\mathrm{Ca}^{2+}$ stores $^{[21,22]}$. ATP mediates the generation of ROS via either P2X or P2Y in different types of cell. It was difficult to determine from our results which subclass or subtype of P2 receptor was responsible for the observed ATP-induced effects in rat mesangial cells. Further studies using specific agonists and antagonists for $\mathrm{P} 2$ receptor subtypes will help us identify the appropriate receptor.

We observed that $\mathrm{p}$-ERK1/2 levels in rat mesangial cells reached their maximum after 5 min of exposure to ATP and decreased gradually during a subsequent period of time. This result suggests that extracellular ATP induces rapid and transient phosphorylation of ERK1/2, consistent with previous studies $^{[12,19,20,23]}$. However, in contrast to previous studies, we found that stimulation of rat mesangial cells with ATP for 60 min resulted in decreased p-ERK1/2 levels when compared with the control. Distinct cell species, differences in cell types or different experimental conditions may account for the differences observed between studies; therefore, further studies are warranted.

Intracellular ROS are generated through both the NADPH 
oxidase system and mitochondrial metabolism. By contrast, the increased production of ROS by mesangial cells under high-glucose conditions is predominantly, although not exclusively, mediated by NADPH oxidase ${ }^{[16]}$. In addition, the NADPH inhibitor DPI has been shown to effectively block the generation of ROS induced by high glucose in mesangial cells $^{[13,16]}$. In our study, DPI only partially inhibited the ATPinduced increase in ERK1/2 phosphorylation suggesting that, in addition to ROS, ATP might activate ERK1/2 through other ROS-independent pathways. It is important to note, however, that NADPH oxidase is at least partially involved in ERK1/2 activation by ATP.

Studies using neutralizing antibodies against TGF- $\beta 1$ have provided convincing evidence that the prosclerotic and hypertrophic effects of high glucose levels are largely mediated by the production and activation of TGF- $\beta 1$ by glomerular mesangial cells ${ }^{[24]}$. Activated ERK can activate Elk-1, a member of the ternary complex factors that enhances the expression of c-fos and promotes subsequent DNA binding of the transcription factor AP-1. An increase in AP-1 binding to DNA has been reported to mediate the expression of TGF- $\beta 1^{[25]}$. Here, we show without a doubt that DPI and PD98059 decrease TGF- $\beta 1$ mRNA levels under high-glucose conditions. Suramin had a similar effect, suggesting that extracellular ATP plays a part in the activation of downstream pathways in response to high glucose in mesangial cells.

Taken together, our results suggest that, in rat mesangial cells, high-glucose conditions increase the extracellular levels of ATP within a short period of time. ATP, in turn, activates ERK1/2, an effect which is at least partially dependent on ROS, leading to the upregulation of TGF- $\beta 1$. As it is known that there are two subclasses of $\mathrm{P} 2$ receptors expressed by mesangial cells and each has several subtypes, future studies will be aimed at determining which subtypes of P2 receptors are involved in this pathway.

\section{Acknowledgements}

This research was financially supported by the Shanghai Natural Science Foundation (No 09ZR1404200) and the National Natural Science Foundation of China (№ 3047627).

\section{Author contribution}

Lin-ping QU, Li-min LU, and Yu HUANG designed research; Lin-ping QU, Hong XUE, Ping YUAN, Li ZHOU performed research; Lin-ping QU, Li ZHOU analyzed data; Lin-ping QU, Tai YAO, Yu HUANG, and Li-min LU wrote the paper.

\section{References}

1 Schwiebert EM. ATP release mechanisms, ATP receptor a signalling along the nephron. Clin Exp Pharmacol Physiol 2001; 28: 340-50.

2 Burnstock G, Kennedy C. Is there a basis for distinguishing two types of P2-purinoceptor? Gen Pharmacol 1985; 16: 433-40.

3 North RA. Molecular physiology of P2X receptors. Physiol Rev 2002; 82: 1013-67.

4 Fischer W, Krügel U. P2Y receptors: focus on structural, pharmacological and functional aspects in the brain. Curr Med Chem 2007; 14: 2429-55.

5 Schwiebert EM, Zsembery A. Extracellular ATP as a signaling molecule for epithelial cells. Biochim Biophys Acta 2003; 1615: 7-32.

6 Gordon JL. Extracellular ATP: Effects, sources and fate. Biochem J 1986; 233: 309-19.

7 Chan CM, Unwin RJ, Bardini M, Oglesby IB, Ford AP, TownsendNicholson A, et al. Localization of P2X1 purinoceptors by autoradiography and immunohistochemistry in rat kidneys. Am J Physiol 1998; 274 (4 Pt 2): F799-804.

8 Bailey M, Hillman K, Unwin RJ. P2 receptors in the kidney. J Auton Nerv Syst 2000; 81: 264-70.

9 Vonend O, Oberhauser V, von Kügelgen I, Apel TW, Amann K, Ritz E, et al. ATP release in human kidney cortex and itsmitogenic effects in visceral glomerular epithelial cells. Kidney Int 2002; 61: 1617-26.

10 Schwiebert EM, Kishore BK. Extracellular nucleotide signaling along the renal epithelium. Am J Physiol Renal Physiol 2001; 280: F94563.

11 Nishiyama A, Rahman M, Inscho EW. Role of interstitial ATP and adenosine in the regulation of renal hemodynamics and microvascular function. Hypertens Res 2004; 27: 791-804.

12 Vonend O, Grote T, Oberhauser V, Von Kügelgen I, Rump LC. P2Yreceptors stimulating the proliferation of human mesangial cells through the MAPK42/44 pathway. Br J Pharmacol 2003; 139: 111926.

13 Lee HB, Yu MR, Yang Y, Jiang Z, Ha H. Reactive Oxygen Speciesregulated signaling pathways in diabetic nephropathy. J Am Soc Nephrol 2003; 14: S241-5.

14 Noguchi T, Ishii K, Fukutomi H, Naguro I, Matsuzawa A, Takeda K, et al. Requirement of reactive oxygen species-dependent activation of ASK1-p38 MAPK pathway for extracellular ATP-induced apoptosis in macrophage. J Biol Chem 2008; 283: 7657-65.

15 Parvathenani LK, Tertyshnikova S, Greco CR, Roberts SB, Robertson $\mathrm{B}$, Posmantur R. P2X7 mediates superoxide production in primary microglia and is up-regulated in a transgenic mouse model of Alzheimer's disease. J Biol Chem 2003; 278: 13309-17.

16 Xia L, Wang H, Goldberg HJ, Munk S, Fantus IG, Whiteside Cl. Mesangial cell NADPH oxidase upregulation in high glucose is protein kinase $\mathrm{C}$ dependent and required for collagen IV expression. Am J Physiol Renal Physiol 2006; 290: F345-56.

17 Solini A, lacobini C, Ricci C, Chiozzi P, Amadio L, Pricci F, et al. Purinergic modulation of mesangial extracellular matrix production role in diabetic and other glomerular diseases. Kidney Int 2005; 67: 875-85.

18 Dichmann S, Idzko M, Zimpfer U, Hofmann C, Ferrari D, Luttmann W, et al. Adenosine triphosphate-induced oxygen radical production and CD11b up-regulation: $\mathrm{Ca}^{++}$mobilization and actin reorganization in human eosinophils. Blood 2000; 95: 973-8.

19 Huwiler A, van Rossum G, Wartmann M, Pfeilschifter J. Stimulation by extracellular ATP and UTP of the stress-activated protein kinase cascade in rat renal mesangial cells. Br J Pharmacol 1997; 120: 807-12.

20 Harada H, Chan CM, Loesch A, Unwin R, Burnstock G. Induction of proliferation and apoptotic cell death via $\mathrm{P} 2 \mathrm{Y}$ and $\mathrm{P} 2 \mathrm{X}$ receptors, respectively, in rat glomerular mesangial cells. Kidney Int 2000; 57: 949-58.

21 Kennedy C. The discovery and development of P2 receptor subtypes. J Auton Nerv Syst 2000; 81: 158-63.

22 Di Virgilio F, Solini A. P2 receptors: New potential players in atherosclerosis. Br J Pharmacol 2002; 135: 831-42.

23 Ahmad S, Ahmad A, Ghosh M, Leslie CC, White CW. Extracellular ATPmediated signaling for survival in hyperoxia-induced oxidative stress. J Biol Chem 2004; 279: 16317-25.

24 Shao Y, He M, Zhou L, Yao T, Huang Y, Lu LM. Chronic angiotensin (1-7) injection accelerates STZ-induced diabetic renal injury. Acta Pharmacol Sin 2008; 29: 829-37.

25 Isono M, Cruz MC, Chen S, Hong SW, Ziyadeh FN. Extracellular signalregulated kinase mediates stimulation of TGF-beta1 and matrix by high glucose in mesangial cells. J Am Soc Nephrol 2000; 11: 222230 . 